\title{
Refused derived fuel pellets from municipal solid waste and rice husk
}

\author{
M. K. Iqbal ${ }^{1 *}$, A. Nadeem ${ }^{2}$ and M. T. Butt ${ }^{1}$ \\ ${ }^{I}$ PCSIR Laboratories Complex Lahore, Pakistan \\ ${ }^{2}$ GCW Baghbanpura Lahore, Pakistan
}

\begin{abstract}
The objective of this study was to optimize the parameters for the development of refused derived fuel (RDF) pellets from municipal solid waste (MSW) and rice husk by using Response Surface Methodology (RSM). In this a systematic study was conducted, where three parameters were varied according to RSM factorial design. The binder concentration (5-10\%) pressure (700-1200 psi) and retention time (3-7 minutes) were used for RDF pellet development under hydraulic press, measured hardness bulk density (BD) and durability (DU). The $\mathrm{T}_{3}$ treatment results revealed the highest pellet hardness, bulk density, and durability $25 \mathrm{~kg}, 805 \mathrm{~kg} / \mathrm{m}^{3}, 99 \%$ respectively by application binder concentration (5\%), pressure (1200 psi) and retention time (5 minutes). The experimental data on

Received: 12 February 2019

Revised: 02 April 2019

Accepted: 06 May 2019 response variables were fitted into quadratic polynomial model using the multiple regression analysis and found that it was statistically significant quadratic model. The RDF physical chemical and mechanical characteristics were also evaluated and found their relationship between HHV, carbon, ash, DU, BD and energy density. The ash contents were inversely proportional to DU and HHV whereas DU was directly related to BD.
\end{abstract}

DOI: https://doi.org/10.3329/bjsir.v54i4.44567

Keywords: Optimization; RDF; Moisture; Hardness; Bulk density; RSM

\section{Introduction}

Energy system of any country is a fundamental driver of social and economic development. Pakistan's energy structure is still under-developed, insufficient and poorly managed; leads to develop an energy system with more renewable energy matrix, reduction of greenhouse gases and meets the Montreal protocol. Biomass is one of the most important renewable energy source, can be used due to their attractive properties like low production cost, low acid gas emission and no net carbon dioxide (Jiang et al., 2014; Garcia-Maraver et al., 2015). These are available in bulk quantities and their primary sources are agricultural residues, forest products, energy crops and unplanned municipal solid waste (MSW).

In recent years research of co-palletization has attracted widespread attention due to high moisture contents asymmetrical shape size low bulk density and use in original form subjects of biomass and MSW. The use of co-pelletized or densified fuels have improved bulk density, handling conveyance efficiency feed stock uniformity and compositional quality (Hoover et al., 2014). The final quality of pellets depends on the raw material properties and palletization process variables like particle size, die temperature, lignin concentration, pressure, binder concentration, residence time and moisture contents. The palletization process variables can be optimized for production efficiency and better quality of finished product as per specification of biomass properties (Carone et al., 2011).

Previous studies used the single-factor optimization to assess the best process conditions for RDF pellets development which is unreliable and may lead to misinterpretation of results. Now a days statistics-based experimental design (RSM) has been reported to the literature, which is time saving and lessen the error in determining the interactive consequence of process parameters (Iqbal et al., 2015). Many researchers used RSM technology to investigate the impact of moisture, pressure and temperature on pellet density and 
hardness (Tumuluru, 2011) but still there is no extensive research work has been conducted regarding the optimization of RDF pellets from MSW and rice husk under pressure, binder concentration and residence time conditions. Therefore the main objective was to investigate the influence of pressure, binder concentration and residence time on MSW and rice husk RDF pellets hardness and its characteristics.

\section{Materials and methods}

\section{Feed stock}

MSW was collected from Muslim Town Lahore and haulted to PCSIR RDF Plant. MSW was segregated manually after conning and quartering for representative sample. The representative sample physical composition was food waste 40.91 \pm 2.34 ; paper ( tetra pack) $13.7 \pm 1.36$; leather and rubber $11.15 \pm 1.08$; cloth $18.46 \pm 1.54$; plastic ( polyethene) $6.59 \pm$ 3.17 ; others $9.18 \pm 2.15$ (Table-I). The rice husk was purchased from local market and crushed up to1-2mm with biomass grinder and determined the air dry moisture (Bailey and Baldini, 2007).

Table I. Physical characterization of MSW

\begin{tabular}{lccc}
\hline Type of waste & \multicolumn{2}{c}{$\begin{array}{c}\text { Percentage } \\
\text { composition }\end{array}$} & Units \\
\hline Food waste & $40.91 \pm 2.34$ & $\%$ \\
Paper (include tetra pack) & 13.7 & \pm 1.36 & $\%$ \\
Leather and rubber & $11.15 \quad \pm 1.08$ & $\%$ \\
Cloth & $18.46 \quad \pm 1,0 \leq$ & $\%$ \\
Plastic (polythene) & $6.59 \pm 3.17$ & $\%$ \\
Others & 9.18 & \pm 2.15 & $\%$ \\
\hline
\end{tabular}

\pm : S.D of three replicates

Optimization of RDF pellets formation by RSM

The RDF pellets development from MSW and biomass was optimized using Box-Behnken design with parameters retention time pressure and binder concentration. It consist of three levels low $(-1)$ medium $(0)$ and high $(+1)$. The preset ranges of independent variables for RDF hardness optimization were as binder concentration (5-10\%) pressure (700-1200 psi) and retention time (3-7 $\mathrm{min}$ ) (Table-III). The present experiment was employed to fit the second order polynomial model, which indicates the required experiments trials 15. All the experiments were carried out in triplicates according to design matrix, which was based on number of variables. The independent variable and the mathematical relationship of response $\mathrm{Y}_{1}$ of these variables were approximated by quadratic polynomial equations for hardness optimization.

$\mathrm{Y}_{1}=\beta_{0}+\beta_{1} \mathrm{X}_{1}+\beta_{2} \mathrm{X}_{2}+\beta_{3} \mathrm{X}_{3}+\beta_{11} \mathrm{X}_{1}^{2}+\beta_{22} \mathrm{X}_{2}^{2}+\beta_{33} \mathrm{X}_{3}^{2}+\beta_{12} \mathrm{X}_{1} \mathrm{X}_{2}+\beta$ ${ }_{13} X_{1} X_{3}+\beta_{23} X_{2} X_{3}$

$Y_{1}$ is the predicted response, $\beta_{0}$ is the constant, $\beta_{1}, \beta_{2}, \beta_{3}$ are the linear co-efficient, $\beta_{11}, \beta_{22}, b \beta_{33}$ are the quadratic coefficient and $\beta_{12}, \beta 13, \beta 23$ are the cross-product coefficients.

The optimum values of the selected variables were obtained by solving the regression equation. The statistical software design (version: 16) was used for experimental design data analysis and graph plotting.

\section{Die drawing}

Fig. 2 illustrates the development of RDF by hydraulic press. It shows the passage of the raw material; MSW and biomass along with binder to make pellets through various steps. Its schematic hollow cylinder of M.S (iron) $127 \mathrm{~mm}$ in length, internal diameter is $50 \mathrm{~mm}$ from the upper sides

In order to develop RDF pellets the MSW and biomass were passed from $1 \mathrm{~mm}$ sieve to homogenize and remove any metal or hard material that impair the die during pellet formation. The binder concentration was prepared as per experimental design manually mixed with MSW and biomass mixture and put into die to develop RDF pellets.

The die was placed on cleaned plate of hydraulic press (60 Ton) and specific composition was charged manually into die main cylinder and insured to reduce the spaces between the mixture particles. Iron plunger was inserted in to die by applying pressure and time to make pellets as per RSM design. The pellets were stored in sealed plastic bags at controlled laboratory conditions (Temp: $25^{\circ} \mathrm{C}, \mathrm{H}: 35-40 \%$ ) to examine physical and chemical properties of RDF pellets.

\section{Characteristics of RDF pellets}

\section{Proximate ultimate and metal analysis}

The proximate ultimate and metal analysis of MSW rice husk and RDF samples developed during different trials were conducted (Bailey and Baldini, 2007).

\section{Calorific value and energy density}

The calorific value or higher heating values of feed stock and pellets were determined by using the Bomb Calorimeter (Parr-6200) three times and average results were reported 
with standard deviation. The lower heating value was also determined (Bailey and Baldini, 2007), The hydrogen contents were taken from ultimate analysis.

The Energy density was calculated by following formula:

$(\mathrm{E})=\mathrm{BD} * \mathrm{LHV} \mathrm{E}: \mathrm{MJ} / \mathrm{m}^{3} ; \quad \mathrm{BD}: \mathrm{kg} / \mathrm{m}^{3} ; \mathrm{LHV}: \mathrm{MJ} / \mathrm{kg}$

\section{Bulk density}

The bulk density was determined of trial 1,3,5 and 13 pellets by measuring the volume, mass and dimension according to CEN/TS 15103 and 15150 respectively. The pellets were randomly selected from each trail and reported the average results.

\section{Durability}

The pellet samples were sieved to remove the fines before analysis of durability. The pellets of trial 1,3,5 and 13 were $(500 \mathrm{~g})$ subjected separately in perforated tumbler for the period of 5 minutes to collide at $50 \mathrm{rpm}$ with each other and with hard surface of the tumbler. After completing the cycle of 5 minutes the pellets were collected separately; reweighed and the difference in percentage was calculated that depict the durability of pellets (ASABE, 2007).

$$
\text { Durability }=\frac{\text { mass of pellet after tumbling }}{\text { mass of pellet before tumbling }} \times 10
$$

\section{Hardness}

The hardness of RDF pellets was analyzed with single press unit with hemisphere end rods. The compressive force was applied to the center of cylindrical pellets after placing horizontal on steel plate. The tester speed was $2 \mathrm{~mm} / \mathrm{min}$ and recorded the maximum force when the pellet break/fracture. The Meyer hardness was calculated by following equation (Lam et al., 2011):

$$
H m=F / 3.14(D h-h 2)
$$

Where $\mathrm{h}$ is the indentation depth $(\mathrm{mm}) ; \mathrm{F}$ is fracturing force in " $\mathrm{N}$ " and $\mathrm{D}$ is the diameter of rod in $\mathrm{mm}$.

\section{Statistical analysis}

Each physico-chemical characteristics of feed stock and RDF pellets of various trials were analyzed three times and their results were reported as an average along with standard deviation.

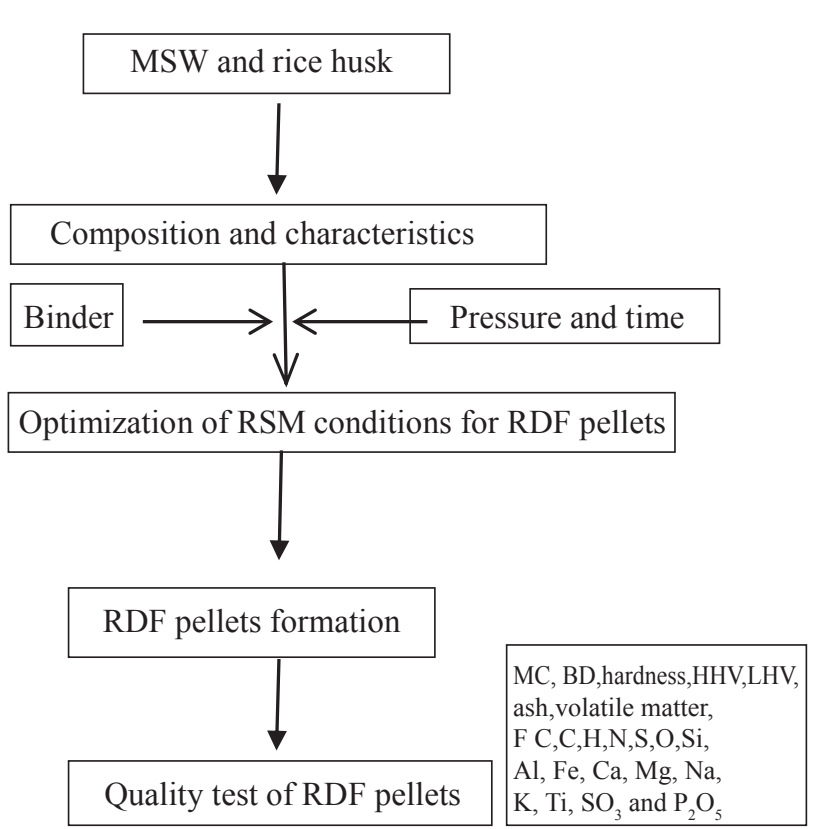

Fig. 1. Flowsheet of process

\section{Results and discussion}

The RDF pellets hardness was optimized by using the RSM technology with three parameters binder concentration pressure and residence time. The MSW and rice husk was used as raw material for pellet development and flowsheet of process as

\section{Characteristics of feed stock}

The MSW sample comprised of paper $(13.7 \%)$, leather and rubber $(11.15 \%)$, cloth $(18.46 \%)$, plastic $(6.59 \%)$ and food waste $(40.91 \%)$. The moisture of MSW (50.67\%) was reduced by the addition of rice husk and its elemental composition has impact on physical and chemical properties of RDF due to ash produced during its combustion. The mineral fractions contained typically the elements $\mathrm{Si}, \mathrm{Al}, \mathrm{Fe}$, $\mathrm{Ca}, \mathrm{Mg}, \mathrm{Na}, \mathrm{K}, \mathrm{S}$ and $\mathrm{P}$. These elemental compositions vary according to the nature of waste material or its source (Table-II). It effects on sintering softening and melting temperature of RDF.

\section{Optimization of RDF pellets hardness through RSM}

There are various parameters like particle size, temperature, pressure, moisture, binder concentration, retention time and die shape for RDF pellet formation. All these factors impart 
Table II. Proximate, ultimate and metal analysis of feed stock and RDF

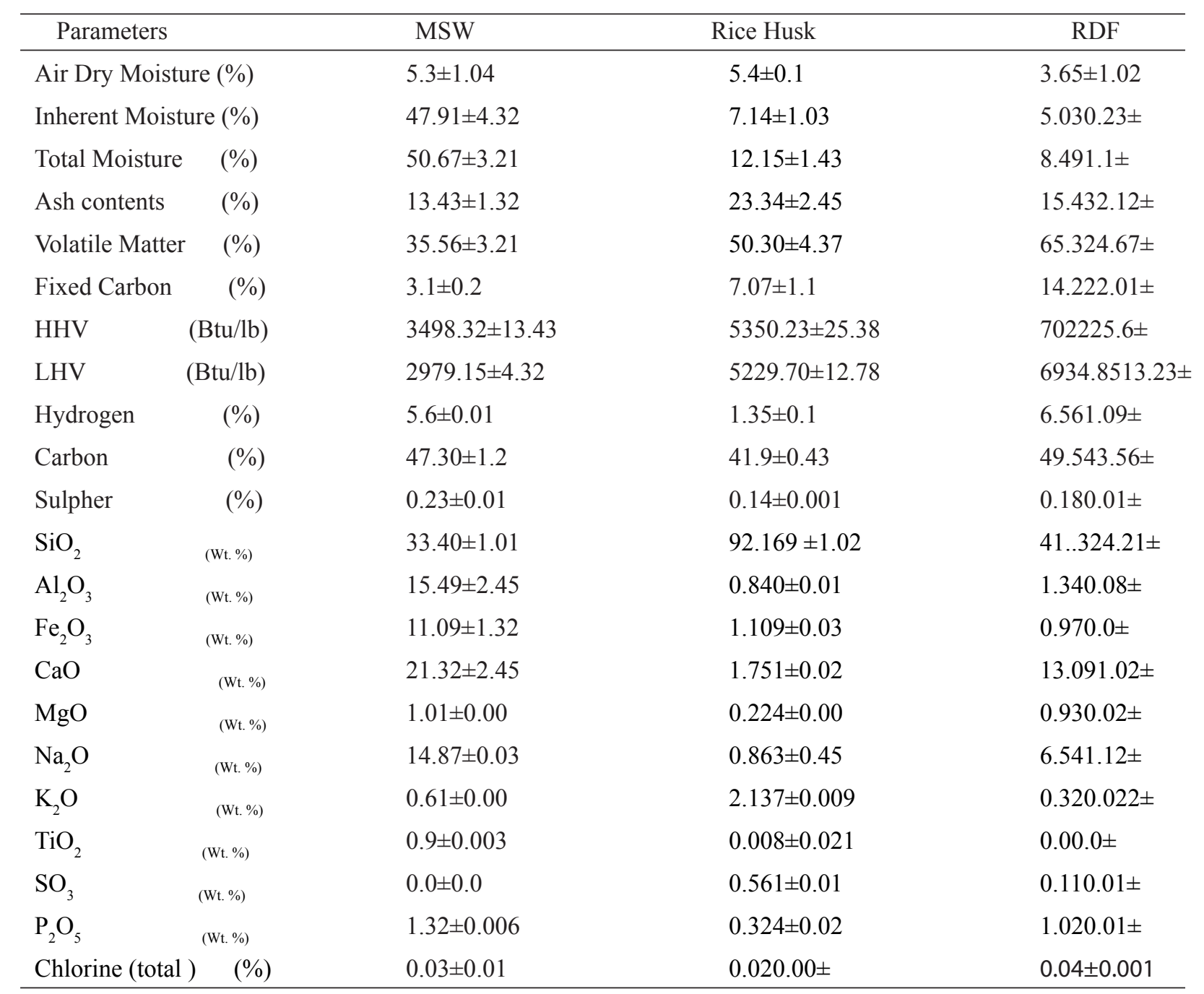

$\pm:$ SD of three replicates (SD: standard deviation)

their impact on pellet geometry. The pressure played a key role in development of RDF pellets which is directly proportional to bulk density (Holm et al., 2006). It made stronger bond between particles by diffusion of molecules. Moreover the retention time also important factor for RDF pellet development which supported by Li and Liu (2000) that with low pressure and high retention time RDF pellets produced of high bulk density and hardness. Moreover various binders are available i.e lingo sulfate, starch, bentonite and proteins. Each had own properties but sulphate containing compounds are not suitable for boiler life and efficiency. In this study the binder was developed in laboratory and its different concentration were used during whole process. The trial 3 and 6 results were not similar even with same pressure (1200 psi) and with different binder concentration and time. It means excess binder concentration and time had no impact on pellet hardness. In the same way trial 12 had the same pressure like trial 3 and 6 but the hardness was 6 and $4 \%$ less respectively than trial 3 and 6 . Furthermore minimum pressure also no impact or influence on RDF pellet hardness as observed in trial 1,4, 9 and 13 (Table III). In these trials the predicted and experimental values had also no much difference. It depicted that optimized condition for pellet development required the combination of different factors involved in pellets development. The higher concentration of binder had no momentous effect because higher binder concentration reduces the spaces between particles that make bridge for the 
Table III. Box-Behnken design matrix along with experimental and predicted values for RDF hardness optimization

\begin{tabular}{cccccc}
\hline Std & pressure & Time & Binder concentration & Experimental & Predicted \\
\hline 1 & -1 & -1 & 0 & 13.3 & 13.05 \\
2 & 0 & +1 & +1 & 17.8 & 17.41 \\
3 & +1 & 0 & -1 & 25.0 & 24.78 \\
4 & -1 & +1 & 0 & 14.0 & 14.17 \\
5 & 0 & +1 & -1 & 20.0 & 19.96 \\
6 & +1 & +1 & 0 & 24.5 & 24.75 \\
7 & 0 & 0 & 0 & 18.0 & 18.00 \\
8 & 0 & 0 & 0 & 18.0 & 18.00 \\
9 & -1 & 0 & -1 & 15.0 & 14.86 \\
10 & +1 & -1 & 0 & 22.0 & 21.82 \\
11 & 0 & -1 & -1 & 15.9 & 16.28 \\
12 & +1 & 0 & +1 & 23.5 & 23.63 \\
13 & -1 & 0 & +1 & 14.0 & 14.21 \\
14 & 0 & 0 & 0 & 18.0 & 18.00 \\
15 & 0 & -1 & +1 & 13.3 & 13.05 \\
\hline
\end{tabular}

development of pellets. The results of trial $2,57,8$ and 14 could not support for the storage or transportation of RDF pellets because their hardness values very different but better than trial no 15. These results accords with the approach depicted by Rhen et al. (2005) during their study the optimized moisture, pressure and time have the good impact on pellets formation. Present results had mega difference with international standards because the hydraulic press was specifically adjusted for maximum time for pellets development where as in extruder or other pellets process had less time for pellet development.

The variables of design matrix for RDF pellets development were coded and presented in table (III) along with predicated and experimental values. These values were determined through quadratic model fitting technique software design. In this statistical model the experimental data was used to apply the multiple regression analysis for the development of RDF pellets from MSW and rice husk under parameters of pressure retention time and binder concentration.

This model was investigated by F-test and the analysis of variance (ANOVA) for the response surface quadratic model is presented in Table-IV. The F value (186.26) depicted that the model is significant because the probability values are very low (P- 0.000) less than 0.05 showed that the RDF pellets hardness results are fitted well by a second order response surface plot. The same observation had been found by different authors in their fields (Iqbal et al., 2015; Rhen et al., 2005).

It is another way to note the significant of model was the lack-of-fit values of effecting parameters pressure, retention time, binder concentration, pressure ${ }^{2}$, retention time ${ }^{2}$, binder concentration $^{2}$, pressure and retention time and binder concentration, pressure and binder concentration values. The goodness of model was tested by determination coefficient (regression coefficient) $\mathrm{R}^{2}$ and by adjusted $\mathrm{R}^{2}$ (multiple correlation coefficients $\mathrm{R}$ ). The value of determination coefficient $\mathrm{R}^{2}$ for $\mathrm{RDF}$ hardness optimization $(99.70 \%)$ indicates that only $0.3 \%$, was not explained by the model. In addition the adjusted coefficient (Adj. $\mathrm{R}^{2}=99.17 \%$ was too high, depicted that significant and goodness of the experimental work and closer the values of adjusted $\mathrm{R}^{2}$ to 1 , indicates the better correlation between experimental and predicted values.

The predicted $\mathrm{R}^{2}$ for $\mathrm{RDF}$ hardness was $99.70 \%$ reasonable agreement with the adjusted $\mathrm{R}^{2}(99.17 \%)$ between the 
Table IV. Analysis of variance (ANOVA) and estimated regression coefficients for RDF pellets hardness optimization

\begin{tabular}{|c|c|c|c|c|c|c|c|}
\hline \multirow{2}{*}{$\begin{array}{l}\text { Source } \\
\text { RDF Hardness }\end{array}$} & \multirow[t]{2}{*}{ Df } & \multirow[t]{2}{*}{ Seq SS } & \multirow[t]{2}{*}{ Adj SS } & \multirow[t]{2}{*}{ Adj MS } & \multirow[t]{2}{*}{$\mathrm{F}$} & \multicolumn{2}{|l|}{$\mathrm{P}$} \\
\hline & & & & & & & \\
\hline \multirow[t]{9}{*}{ (ANOVA) } & Regression & 9 & 207.023 & 207.023 & 23.0025 & 186.26 & 0.000 \\
\hline & Linear & 3 & 197.033 & 3.382 & 1.1274 & 9.13 & 0.018 \\
\hline & Square & 3 & 6.395 & 6.395 & 2.1317 & 17.26 & 0.005 \\
\hline & Interaction & 3 & 3.595 & 3.595 & 1.1983 & 9.70 & 0.016 \\
\hline & Residual error & 5 & 0.618 & 0.618 & 0.1235 & & \\
\hline & Lack-of- Fit & 3 & 0.618 & 0.618 & 0.2058 & & \\
\hline & Pure Error & 2 & 0.000 & 0.000 & 0.000 & & \\
\hline & Total & 14 & 207.640 & & & & \\
\hline & Term & & & Coef & SE Coef & $\mathrm{T}$ & $\mathrm{P}$ \\
\hline \multicolumn{8}{|c|}{ RDF Hardness } \\
\hline \multirow[t]{11}{*}{ (Regression) } & Constant & & & 9.4155 & 4.49731 & 2.094 & 0.090 \\
\hline & pressure & & & -0.01633 & 0.00622 & -2.625 & 0.047 \\
\hline & Time & & & 2.4512 & 0.62756 & 3.906 & 0.011 \\
\hline & Binder Concen & & & 0.1150 & 0.5429 & 0.211 & 0.841 \\
\hline & pressure $*$ pr & & & 0.00002 & 0.0000 & 5.878 & 0.002 \\
\hline & Time $*$ Time & & & -0.15625 & 0.04572 & -3.417 & 0.019 \\
\hline & Binder Concent & on * Binder Con & centration & 0.04800 & 0.02926 & 1.640 & 0.162 \\
\hline & pressure $*$ Tim & & & 0.00090 & 0.00035 & 2.561 & 0.051 \\
\hline & pressure $*$ Binc & Concentration & -0.00020 & 0.00028 & -0.711 & 0.509 & \\
\hline & Time * Binder & ncentration & & -0.16500 & 0.03514 & -4.695 & 0.005 \\
\hline & & & & $\mathrm{R}^{2}: 99.70 \%$ & & $\mathrm{R}^{2}$ (adj) & \\
\hline
\end{tabular}

experimental and predicted value for RDF hardness optimization (Table-IV).

In present study the precision ratio for RDF hardness was greater than 4 which indicated that the model had an acceptable signs. The fitted response surface plot was generated by statistically significant above the model by design expert program to know the interface between parameters during the optimization RDF pellets hardness. The hardness of pellets impact on the shelf life of RDF because during transportation and storage RDF material reduces the $\mathrm{BD}$.

Moreover during optimization of RDF pellets hardness the contour plots were plotted and one parameter was plotted at any one time on $\mathrm{X}$ and other on $\mathrm{Y}$ axis and the yield in $\mathrm{Z}$-axis whereas other residual variables automatically adjusted by software during plotting at the middle.

The contour plot shape (elliptical, circular) confirmed the interaction between parameters was significant or not. In this study the circular plots showed the interaction and relationship between parameters during hardness optimization was significant and more dependent on each other because the concentration of binder impact on the hardness of pellets along with pressure. The increase of pressure up to 1200 psi impact good on hardness but when the pressure decreased then hardness of pellets also decreased and pellets development was not good and showed spaces between particles that depicted the pressure was less and also no effect of binder.

Whereas when too much pressure the hardness of pellets increased which hinder the burning and volatility. The particle needed the appropriate space for oxygen and burning so hardness of RDF should be with in prescribed standards. Present study results are also in line with Zamorano et al. (2011).

The hardness of RDF pellets was directly related to the intense color of the contour plot means as the color become dense the more hardness of RDF pellets was found (Fig. 3). 
These figs depicted that concentration of binder impact on hardness of pellets whereas too much high concentration has no impact on hardness. Similarly the retention time also have great contribution in development of pellets but the retention time greater than 5 mins had no impact on results. The present results are in agreement with Hlaba et al. (2016).

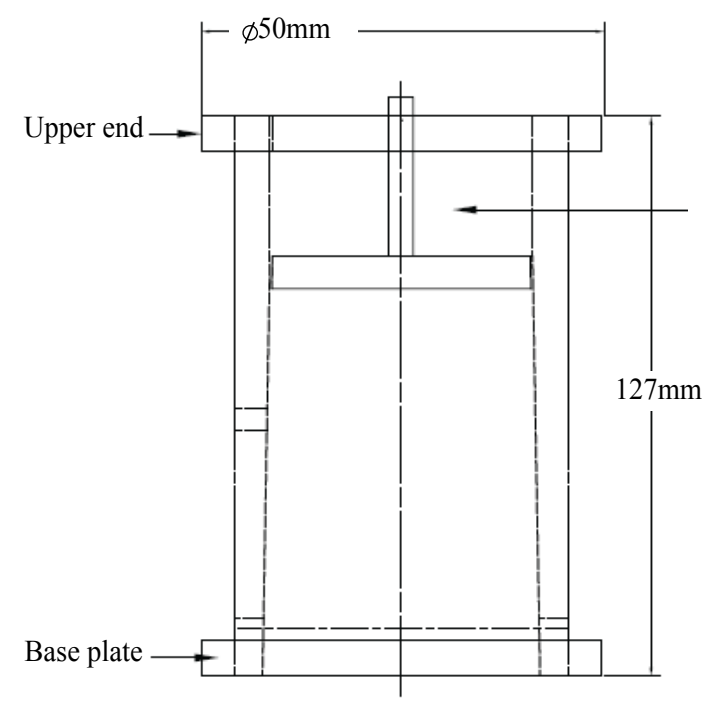

Fig. 2. Design of RDF Die

By solving the Eq.1 using the software the optimum values for hardness optimization were as binder concentration (5\%) retention time ( 5 mins) and pressure 1200 psi for best RDF pellet. The predicted values for RDF pellets hardness was 24.78 $\mathrm{kg}$ close to the experimental work $(25 \mathrm{~kg})$ in this experiment.

\section{Validation of model}

Various experimental works were performed during the optimization of process conditions for the development of RDF pellets of high hardness value required for the storage and transportation. The pressure had a key role along with retention time and binder but the excess binder created the problems during pellets development and maximum time had also no significance for mature results. So under RSM umbrella optimized conditions to produce the pellets of high hardness $(25 \mathrm{~kg})$ are pressure $1200 \mathrm{psi}$, retention time 5 mins and binder concentration also 5\%. These conditions were better for RDF pellet development.

\section{Characteristics of RDF pellets}

\section{Calorific value and energy density}

The higher heating values of all RDF pellets produced during different trials showed the values $13.78 \mathrm{Mj} / \mathrm{kg}\left(\mathrm{T}_{1}\right), 15.17$ $\mathrm{Mj} / \mathrm{kg} \quad\left(\mathrm{T}_{3}\right), 15.03 \mathrm{Mj} / \mathrm{kg}\left(\mathrm{T}_{5}\right)$ and13.12 $\mathrm{Mj} / \mathrm{kg}\left(\mathrm{T}_{13}\right)$. The results in present study were almost alike due to same composition of rice husk and MSW in all trials. The carbon contents were related to the percentage of lignin present in rice husk. The lignin had the low degree of oxidation and a high combustion value (Garcia-Marawer, 2015).

Energy density was calculated by multiplying the BD with LHV. The highest values were obtained by $\mathrm{T}_{3}$ and $\mathrm{T}_{5}$ due to their high BD. The high BD was due to the impact of pressure binder concentration and appropriate time as defied by RSM. The energy density of $\mathrm{T}_{3}$ was $16 \%$ and $5.7 \%$ more than $\mathrm{T}_{13}$ and $T_{1}$ respectively whereas $T_{3}$ and $T_{5}$ results had no

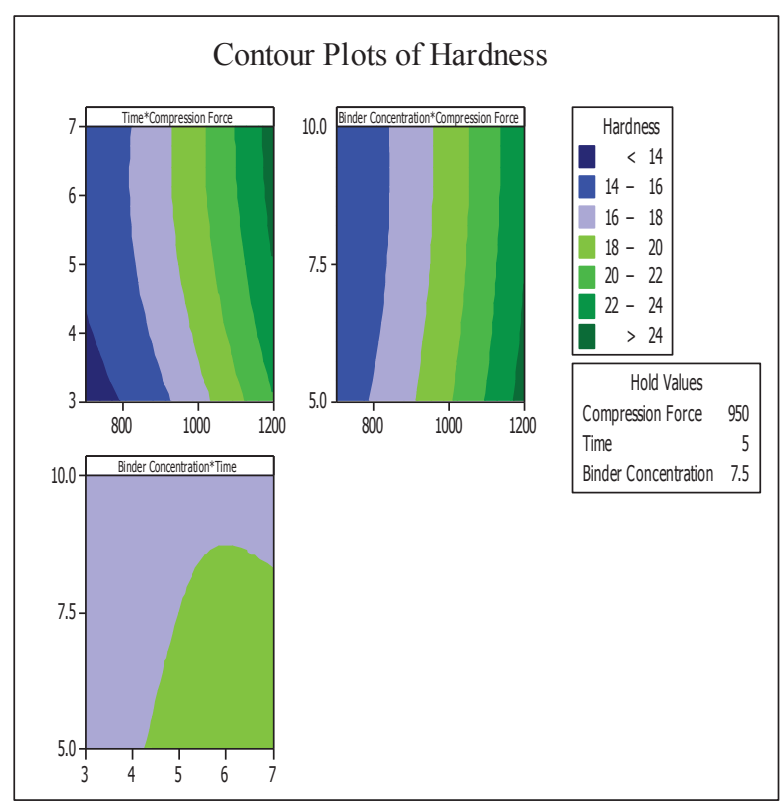

Fig. 3. Three dimensional surface plot for RDF pellets

variation. The RDF pellets of high BD had much more HHV and energy per unit volume. The palletization methodology increased the energy density which reduced the logistic and storage needs. More over the composition of all trials in present study was almost same but the impact of pressure raised BD and HVV (Fig. 4a).

The HVV depends upon carbon and ash and had strong directly proportional relationship. The $\mathrm{T}_{3}$ and $\mathrm{T}_{5}$ hadal most equal HHV and major different from $T_{1}$ and $T_{13}$ due to presence of high ash and moisture (Fig. 4b). Carbon and hydrogen of RDF defined the exothermic reaction during combustion and release $\mathrm{CO}_{2}$ and $\mathrm{H}_{2} \mathrm{O}$ (Biswas et al., 2014). 

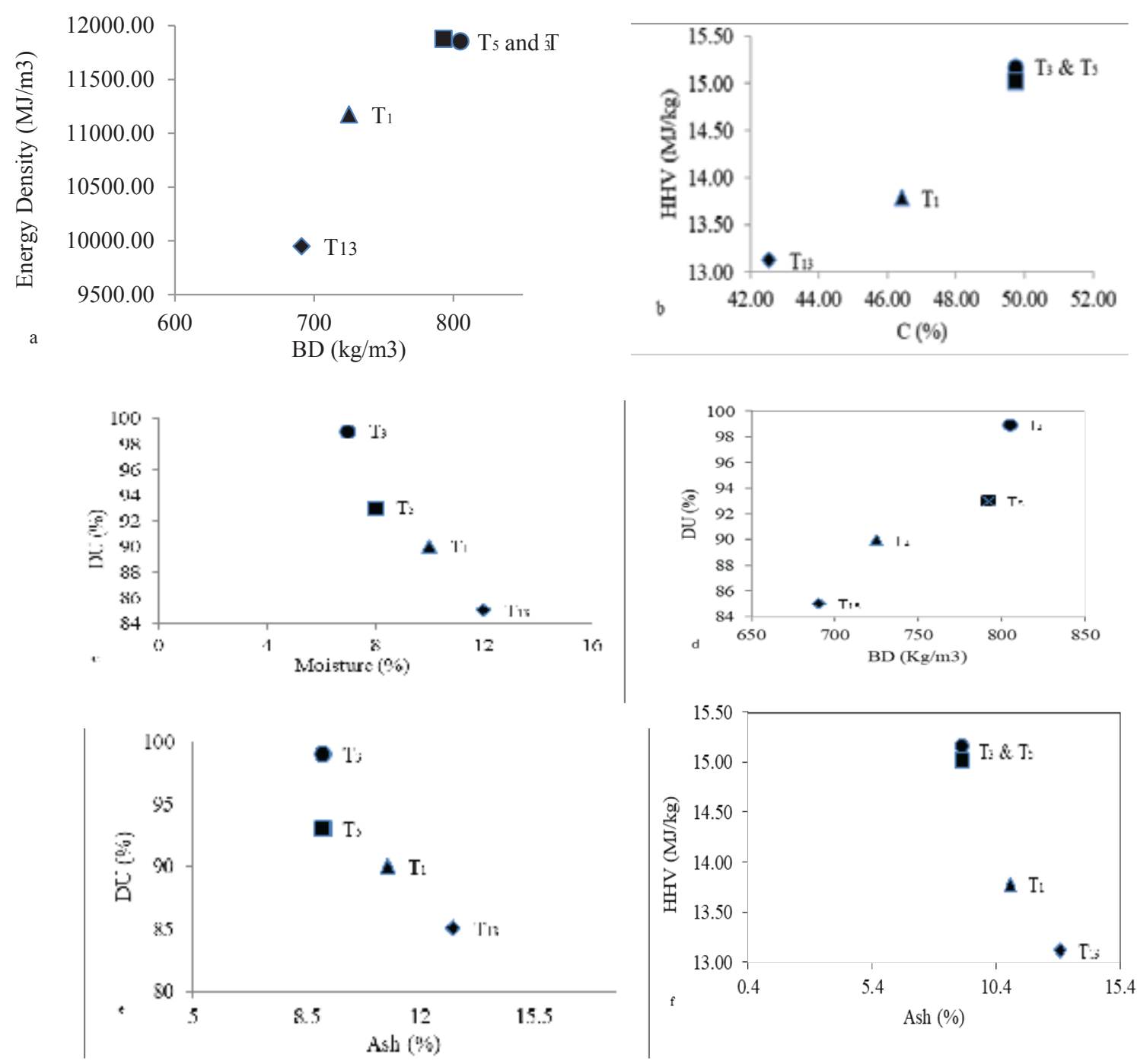

Fig. 4. Effect of relationship on RDF properties (a) E and BD (b) HHV and C (c) DU and moisture (d) DU and BD (e) DU and ash (f) HHV and ash

Durability is the physical strength of pellets to be broken during transportation and storage. There were various factors involved for RDF durability like pressure die size moisture lignin concentration and temperature. In present study the variation in pressure had a great impact on durability along with moisture. When the binder concentration was changed the moisture of the end product was also changed. It means when moisture was too much high or low then durability was affected. The trials having too much moisture had low BD and low DU due to less bonding during compression. When the moisture and pressure were favorable then DU was raised as shown by $\mathrm{T}_{3}$ and $\mathrm{T}_{5}$. On the other hand the $\mathrm{T}_{1}$ and $\mathrm{T}_{13}$ had high moisture and low BD and resultant low DU and hardness. The $\mathrm{T}_{13}$ had less DU than $\mathrm{T}_{3}$ due to high moisture contents of $T_{13}$ than $T_{3}$ (Fig. 4c). The present results were coherent with Tumuluru et al. (2011). In present finding these parameters were inversely proportional to each other. When the moisture was high then DU less. The DU of $\mathrm{T}_{3}$ and $\mathrm{T}_{5}$ were $14.14 \%$ and $8.6 \%$ greater than $\mathrm{T}_{13}$ due to significant difference in their moisture contents. Lattice literature also supported the present finding due to high moisture was the major hindrance during pellet formation and showed the cracks on the body of pellets. 
The BD and DU are interrelated with each other. The RDF pellets having high DU then $\mathrm{BD}$ will also be more but in present scenario (Fig-4d) it was also found that when the value of $\mathrm{BD}$ was more then DU showed some decreasing trend. It means much more pressure is required to achieve high value of DU. The trials $\mathrm{T}_{3}$ and $\mathrm{T}_{5}$ have high $\mathrm{DU}$ than $\mathrm{T}_{13}$ and $\mathrm{T}_{1}$ due to difference in their BD. These results had been supported by Miranda et al. (2015).

In addition there was also another finding during this RDF pellets development that when ash will be more then DU will be low because the lignin and starch concentration were not high. The present findings were coherent with this concept (Fig. 4e).

In addition the same relationship has been found between HHV and ash. The concentration of ash also reflects the carbon as well as HHV. When the ash contents will be higher than HHV will be low. The same observation has been found in this study which was endorsed by other scientist. Apart from that, Gillespie et al. (2013) also concluded in their study that higher sample ash means lower heating values of RDF per unit mass (Fig. 4f).

Moreover, the hardness of RDF pellets had also prominence in literature due to weight of the top pellets on the lower pellets during storage in bins or silos (Gilbert et al., 2009). It provides the quick measure of the quality of pellets as the pellets produce from pellet mill. The pellets hardness results in present finding were different due to variation in moisture pressure BD binder concentration and residence time. These all factors have great impact on hardness of pellets as per defined methodology of RSM.

\section{Conclusion}

RSM technology optimized the process conditions for RDF pellets development from MSW and rice husk and evaluated their physical chemical and mechanical properties. It was found that maximum pressure and residence time with low binder concentration produced high hardness pellets. RDF development technology not only promotes the disposal of MSW and use as alternative energy source. Furthermore RandD is required to develop various formulation based on industrial waste, which can be reutilized for industrial energy process.

\section{References}

ASABE Standards S269.4 (2007), Cubes, pellets and crumbles, Definitions and methods for determining density, durability and moisture content, St. Joseph, Michigan, USA.
Bailey SJ and Baldini NC (2007), Annual book of ASTM standards, ASTM International, USA 4: 775-776.

Biswas AK, Rudolgsson M, Broström M and Umeki K (2014), Effect of pelletizing conditions on combustion behavior of single wood pellet, Applied Energy 119: 79-84.

Carone MT, Pantaleo A and Pellerano A (2011), Influence of process parameters and biomass characteristics on the durability of pellets from the pruning residues of Olea europea L., Biomass Bioener. 35: 402-410.

Garcia-Maraver A, Rodriguez ML, Serrano-Bernardo F, Diaz LF and Zamoranoa M (2015), Factors affecting the quality of pellets made from residual biomass of olive trees, Fuel Process Technol. 129: 1-7. DOI: org/10.1016/j.fuproc.2014.08.018

Gilbert P, Ryu C, Sharifi V and Swithenbank K (2009), Effect of process parameters on palletization of herbaceous crops, Fuel 88: 1491-1497. DOI: org/10.1016/j.fuel.2009.03.015

Gillespie GD, Everard CD, Fagan CC and McDonnell KP (2013), Prediction of quality parameters of biomass pellets from proximate and ultimate analysis, Fuel 111: 771-777. DOI: org/ 10.1016/j.fuel.2013.05.002

Hlaba A, Rabiu A and Osibote OA (2016), Thermochemical Conversion of Municipal Solid Waste: An Energy Potential and Thermal Degradation Behavior Study. Int Jour of Envir Sci and Develop. 7: 661-667.

Holm JK, Henriksen UB, Hustad JE and Sorensen LH (2006), Toward an Understanding of Controlling Parameters in Softwood and Hardwood Pellet Production, Energy and Fuel 20: 2686- 2694.

Hoover AN, Tumuluru JS, Teymouri F, Moore J and Gresham G (2014), Effect of pelleting process variables on physical properties and sugar yields of ammonia fiber expansion pretreated corn stover, Bioresource Technology 164: 128-135. DOI: org/10.1016/ j.biortech.2014.02.005

Iqbal MK, Nadeem A, Sherazi F and Khan RA (2015), Optimization of process parameters for kitchen waste composting by response surface methodology, Int. J. Environ. Sci. Technol. 12: 1759-1768

Jiang L, Liang J, Yuan X, Li H, Li C, Xiao Z, Huang H, Wang H, Zeng G (2014), Co-palletization of sewage sludge and biomass: The density and hardness of pellet, Bioresource Technology 166: 435-443. 
Lam PS, Shahab Sokhansanj S, Bi X, Lim CJ and Melin S (2011), Energy input and quality of pellets made from steam-exploded douglas Fir (pseudotsugd menziesu). Energy Fuel 25: 1521-1528. DOI: org/10. $1021 / \mathrm{ef1} 101683 \mathrm{~s}$

Li Y and Liu H (2000), High Pressure Densification of Wood Residues to Form an Upgraded Fuel, Biomass Bioenergy 19: 177-186.

Miranda T, Montero I, Sepulveda FJ, Arranz JI, Rojas CV, Nogales S (2015), A Review of Pellets from Different Sources, Materials 8: 1413-1427. DOI: org/ 10.3390/ma8041413

Rhen C, Gref R, Sjostrom M and Wasterlund I (2005), Effects of raw material moisture content, densification pressure and temperature on some properties of Norway spruce pellets, Fuel Proces Technol. 87: 11-16. DOI: org/10.1016/j.fuproc. 2005.03 .003
Tumuluru JS, Wright CT, Hess JR and Kenney KL (2011), A review of biomass densifi cation systems to develop uniform feedstock commodities for bioenergy application, Biofuels Bioprod Biorefin 5: 683-707. DOI: org/10.1002/bbb.324

Tumuluru JS (2014), Effect of process variables on the density and durability of the pellets made from high moisture corn stover, Biosystems engineering 119: 44-57.

Zamorano M, Popov V, Rodríguez ML and García-Maraver A (2011), Comparative study of quality properties of pelletized agricultural and forestry lopping residues, Renewable Energy 36: 3133-3140. DOI: org/10.1016/j.renene.2011.03.020 